Психология. Журнал Высшей школы экономики.

2017. T. 14. № 2. C. 338-355. DOI: 10.17323/1813-8918-2017-2-338-355

\title{
ЗАРОЖДЕНИЕ И РАЗВИТИЕ НАЧАТКОВ РЕЧИ У МЛАДЕНЦА В ТЕЧЕНИЕ ПЕРВЫХ НЕДЕЛЬ И МЕСЯЦЕВ ЕГО ЖИЗНИ (0-12 МЕС.)
}

\author{
Т.Н. УШАКОВА
}

${ }^{a}$ ФГБУН Ииститут психологии РАН, 129366, Россия, Москва, ул. Ярославскал, д. 13, к. 1

\begin{abstract}
Резюме
Представлен научный проект, обозначивший направление пути происхождения осмысленного слова у маленького ребенка, начиная с момента его рождения. Реакции детей рассматривались как элементы их адаптивного поведения. Собрана база данных систематических видео-аудиозаписей поведения пяти младенцев от 0 до 12 мес., т.е. в период, предшествующий появлению детских слов, - в так называемый предсловесный период. Разработана специализированная методика анализа видео-аудиозаписей: выделялись три вида голосовых проявлений и четыре вида познавательно-действенных реакций, а также некоторые другие проявления. Получено, что на протяжении времени наблюдения вырисовывается структура реакций, включающая, по крайней мере, две подсистемы - голосовую и познавательно-действенную. Представленные в тексте диаграммы показывают различия в путях развития голосовой и семантической подсистем. Этим схематически показана история проявления каждой из них. Ранние истоки детской речи связаны с формированием всей обозначенной системы, а ее развитие начинается от рождения младенца. Разработано теоретическое представление о зарождении и развитии семантического (субъективного) компонента у младенца в первые месяцы его жизни, появление у него зачаточных форм осмысленности, а также роли оперантного научения в выработке первых детских слов.
\end{abstract}

Ключевые слова: возникновение слова у младенца, голосовые и познавательно-действенные реакции, психологический компонент слова, осмысленность.

Отсчет начала речи у каждого ребенка начинается обычно от момента появления у него первых слов. Ранние детские слова (как правило, «незрелые» по звуковой форме и по заключенному в них психологическому содержанию) становятся, как правило, началом нарастания и расширения лексикона ребенка, а также дальнейшего развития его речевых умений. С этого времени идет отсчет так называемого словесного периода развития малыша, тогда как предшествующий ему - предсловесный, или предречевой.

Относительная простота датировки времени появления словесного периода послужила тому, что он

Исследование поддержано грантом РГНФ, проект № 14-06-00174а. 
практически всегда используется как простой маркер установления момента начала речевого развития. Однако время появления первого детского слова сильно колеблется от ребенка к ребенку. По нашим и литературным, собранным нашей рабочей группой данным ${ }^{1}$, можно утверждать, что раньше 9 мес. первые слова маловероятны. Такие ранние звучания, как «да-да-да», «ма-мама», «па-па-па», бывают вариантами или элементами лепетных последовательностей. Совпадая с существующими формами языка окружающих, они нередко принимаются окружаюшими за первые слова. Появление первых собственно слов наблюдается у здорового малыша обычно к первому году со дня его рождения (10-12 мес.) или же, при возможной случайной задержке, к полутора-двум годам.

Характер и особенности ранних детских слов подробно изучались в нашей стране и за ее пределами. Однако вопрос о том, каким образом, на основании каких правил появляются первые детские слова, остается нерешенным. В то же время вопрос этот имеет первостепенное значение. Дело в том, что появление слова в общем ходе психического развития ребенка свидетельствует о чрезвычайно важном приобретении его психики. Малыш проявляет способность (поначалу несовершенную) соединять производимый им звук с явлением другой природы - мыслью, пониманием.

Осознание значения этого вопроса побуждает внимательно обратить- ся к рассмотрению раннего времени развития младенца. Исследованием этого сложного, порой труднодоступного этапа развития ребенка интересовались крупные специалисты в области детской психологии. Предметом исследований явились разные стороны объекта. Изучались перцептивные возможности младенца (П. Куль); характер звуковых вокализаций, спонтанно развивающихся у него от рождения (Е. Лякco); появление и развитие функции общения с мамой и другими людьми (М. Лисина, М. Томаселло); когнитивные способности младенца, понимание речи (Э. Бейтс, Ж. Пиаже, Е. Сергиенко); поведенческие проявления малыша - «комплекс оживления», общение в раннем возрасте, интенциональные реакции (М. Лисина, С. Белова) и др. Опубликованы монографические исследования линий онтогенеза речевой способности ребенка, включая ранний детский возраст (Ляксо, 2010; Сергиенко, 2006; Томаселло, 2011; Ушакова, 2011). Опираясь на большой экспериментальный материал, полученный во многих лабораториях мира при исследовании «предречевого» развития ребенка, авторитетная исследовательница П. Куль составила схему, отражающую сложность и богатство этого процесса, характеристики и время проявления у младенца разных сторон развития (Kuhl, 2004).

Несмотря на результативность и многочисленность проведенных исследований, остался без ответа

${ }^{1}$ Подбор соответствующих литературных данных проведен нашей сотрудницей Н.М. Лаптевой. 
интересующий нас вопрос о пути соединения звука голоса ребенка с его психологическими переживаниями, имеющими смысловое содержание. П. Куль пишет: «Младенцы осваивают язык с удивительной быстротой, но, как они это делают, остается загадкой» (Ibid., p. 831).

Трудность вопроса о пути развития речевой способности маленького ребенка, как нам представляется, связана с тем, что упускается из вида необходимость определить мотивирующий механизм такого развития. Мы полагаем, что этот механизм строится на принципе адаптации и обучения, как это настойчиво подчеркивалось Б.Ф. Скиннером (Skinner, 1957). По нашему мнению, набор реактивных и перцептивных средств, имеющихся у младенца при рождении, является необходимым багажом, используемым для адаптации к предстоящим жизненным условиям. В литературе показано, что голос новорожденного человеческого ребенка, как и детенышей зверей, а также многих птиц в начальные дни его жизни является значимым поведенческим сигналом, играющим адаптивную роль. О важности его адаптивной роли косвенно, но красноречиво свидетельствует тот факт, что новорожденный ребенок снабжен при рождении минимальным набором адаптивных средств, необходимых для совершения и поддержания первых шагов его существования. А голос включен в этот набор. Поначалу голос малыша связан с несколькими формами его поведенческой активности: едой, комфортом, здоровьем и некоторыми другими. Это значит, что с момента появления здорового младенца на свет его голосовые проявления служат сохранению и адаптации его организма к наличным условиям среды, в данном случае - получению помощи от окружающих. Таким образом, совокупность существующих фактов указывает на поведенческую природу проявлений голосовых реакций младенца (аналогичную точку зрения выражают А.Н. Серков и Д.С. Бережной: Серков, Бережной, 2016).

Из данного тезиса естественно возникает целый ряд вопросов. Оказывает ли влияние поведенческий характер младенческих проявлений на тот путь развития, который заканчивается появлением детского слова? Подчиняются ли правилам адаптивности позднее возникающие формы проявлений младенца? Как долго сохраняется адаптивно-поведенческая роль младенческого голоса и других реакций в последующие недели и месяцы жизни малыша? Меняется ли поведенческий контекст младенческих проявлений, в чем причины происходящих изменений? Ответы на эти вопросы, как мы полагаем, могут быть найдены при систематическом выявлении тех изменений, которые происходят в поведенческой характеристике голосовых и познавательных реакций, а также при рассмотрении их соотношения между собой на протяжении интересующего нас периода.

Адекватным такой задаче было признано применение систематического естественного (не лабораторного) аудио-видеонаблюдения за поведением младенца и сбор соответствующей базы данных. Собранный материал интерпретировался в соот- 
ветствии с рядом разработанных нами и описанных ниже принципов. Применение аудио-видеонаблюдения, по нашему представлению, уместно при поведенческом характере проявлений младенца в репертуаре имеющихся у него способов взаимодействия с окружающим миром.

Сказанное означает, что наша работа строилась на эмпирическом материале, организации специальных экспериментальных условий не предполагалось. В основной массе работы проводилось наблюдение с последующим анализом его результатов. Для проведения анализа потребовалась разработка специализированной методики.

\section{Методика исследования}

\section{Материаль записей}

В качестве эмпирического материала, как уже сказано, использовались аудио-видеозаписи. База данных формировалась путем обращения к коллегам - московским профессиональным психологам, в семьях которых появлялись дети. Собраны данные 5 детей (3 мальчика и 2 девочки) в условиях их свободного поведения. Период наблюдения за каждым ребенком в основном - от 0 до 12 мес. Общий совокупный объем записанных файлов - более 1500 эпизодов. Регистрация поведения малышей непростое дело, требующее затраты времени и внимания записывающе- го человека. В нашем случае записи производились с относительной систематичностью родителями наблюдаемых малышей².

Видеонаблюдение сейчас нередко применяется при изучении раннего речевого онтогенеза ${ }^{3}$. Важной линией его практического использования является выявление аутистических расстройств (Einspieler et al., 2014; Marschik et al., 2012; Saint-Georges et al., 2010; Zappella et al., 2015). В связи c когнитивным и психосоциальным развитием младенца изучается средовой контекст, включающий особенности поведения взрослого (Dimitrova et al., 2015; Hall et al., 2014; и др.). Исследуются закономерности моторного развития младенцев (Fjørtoft et al., 2009; и др.).

Обычным методическим способом является сбор данных фрагментарного, а не сплошного аудио-видеонаблюдения. При соответствующем подходе он дает удовлетворительные результаты. Именно он использовался в упомянутых и близких исследованиях.

В этом плане новаторская разработка произведена в недавнее время профессором Массачусетского технологического института Дебом Роем с группой сотрудников (Roy et al., 2006, 2015). Работа отличается богатой оснащенностью техническими средствами. Предварительно, до появления ребенка, все помещения родительской квартиры были оснащены камерами и микрофонами. На их основе проведены сплошные

${ }^{2}$ Пользуемся случаем, чтобы выразить коллегам свою благодарность за проведенную работу.

${ }^{3}$ Материалы по раннему речевому онтогенезу собраны сотрудницей Института психологии РАН С.С. Беловой. 
видеозаписи жизни сына Д. Роя. Записи продолжались в течение трех лет по 8-10 часов ежедневно. В результате этой работы получен гигантский объем материала, 200000 часов записей, который анализировался при посредстве специальных технологий. Идея (гипотеза) проекта состояла в том, что контекст определяет успешность усвоения слова. По результатам работы, переменные контекста оказались достаточно сильными предикторами появления слов. На этом основании характеристики контекста оцениваются авторами как предикторы появления слов у ребенка. Зафиксированная ситуация определяется как рождение слова малыша ${ }^{4}$.

Эмпирический материал работы чрезвычайно богат, однако трактовка вопроса об условиях возникновения слова у младенца представляется нам недостаточной. Дело в том, что каждое слово языка имеет две стороны: объективную, прежде всего звуковую, и другую - часто называемую субъективной, или семантической.

Вторая из названных характеристик слова высокосущественна при развитии речевой способности ребенка. Однако она не включается в анализ и не обсуждается в публикациях Д. Роя. Результаты его работы трактуются целиком в объективистском плане. Процесс рождения слова рассматривается как результат влияния внешних обстоятельств только на звуковую сторону голосовой продукции мальчика. Этот тезис противоречит как ряду теоретических представле- ний, так и большому кругу международных разработок, в которых эмпирически показано, какое большое значение для развития способности ребенка имеют процессы семантической обработки внешних впечатлений.

\section{Методика анализа видеозаписей, использованная в нашей работе}

Для обработки полученных нами фрагментарных аудио-видеозаписей применялась специализированная методика, основная цель которой состояла в преодолении факторов, дестабилизирующих используемые в анализе показатели. Мы обратили внимание на то, что индивидуальная вариативность явлений в это время оказывается очень большой. Не меньшее значение имеет и то обстоятельство, что поведение младенца первого года жизни представляет собой быстро изменяющийся процесс, имеющий разнообразные поведенческие проявления. Например, комплекс оживления появляется у малыша в 2-3 мес., а далее как форма инициации его контакта со взрослым претерпевает настолько сильные изменения, что явления кажутся несравнимыми. Аналогичным образом исследовательская активность на первом году жизни может проявляться в таких относительно простых формах, как зрительное сосредоточение у новорожденного, а в возрасте нескольких месяцев это может быть сложное манипулирование объектом.

${ }^{4}$ Попутно отметим, что словосочетание «рождение слова» использовалось нами значительно раньше в названии нашей монографии, выпущенной в свет в 2011 г. 
Разнообразие функциональных проявлений делает невозможным длительное, на протяжении года, сквозное отслеживание той общей психофизиологической способности, которая лежит в основании конкретных форм поведенческих проявлений. Задача выявления их общих оснований может успешно решаться при введении кодовых знаков, т.е. при использовании обцих обозначений для явлений, различающихся по форме, но играющих одинаковую функциональную роль в поведении и голосе маленького ребенка как формах его поведения. Именно это и было необходимо для нашей работы. Для маркирования элементов поведения и голоса младенца при исследовании разных этапов раннего младенческого возраста были разработаны и использованы соответствующие кодовые обозначения.

\section{Кодирование познавательньх и голосовых реакций как поведенческих форм проявлений младениа}

В результате предварительного просмотра и прослушивания аудиовидеозаписей были выделены три вида функционально различных голосовых проявлений младенца (Белова и др., 2016). С учетом тех различий, которые существуют в психоакустике (плач, предплач, гласноподобные, согласноподобные и др.), вектор различения голосовых проявлений ребенка в нашем анализе подбирался иначе - в соответствии с целью нашей работы. Он был направлен на то, чтобы способствовать выявлению общей линии сбли- жения голоса младенца с речью окружающих. На основании этого вектора различали следующие голосовые проявления младенца.

В раннем детском голосе выделяли: крик, плач, предплач как витальные формы, идущие от новорожденности, наиболее отдаленные от интересующей нас линии развития речевого голоса. Такие вокализации кодировались как 1) голос негативный - вокализации отрицательной окрашенности - Г-1.

Наряду с ясным проявлением негативных вокализаций после 1-го месяца жизни у младенца возникают и развиваются вокализации положительной или нейтральной окрашенности, со временем приобретающие характер гласноподобных, затем согласноподобных и других типов звуков. Такие вокализации кодировались как 2) голос нейтрально-позитивный - Г-2.

Наиболее полные формы голосовых проявлений младенца возникаюо во второй половине первого года жизни. В это время проявляются вокализации с чередованием взрослого и детского голосов (имитация диалога), обнаруживаются подражание интонации взрослых, различные варианты звукоподражания малышом речи окружающих людей: имитация слогов, вопросительной интонации и др. Все эти варианты мы квалифицировали как 3) голос сложный - Г-3.

По другим принципам был организован анализ поведения младенца. Здесь основанием для различения и кодирования являются действия младенца и направленность этих действий на те или другие объекты. 
Различали четьре вида поведения:

1) ориентировочно-исследовательское поведение (П-1) связано с познанием предметного мира. Начальными его формами являются зрительное сосредоточение, стремление ухватить близлежащий объект. Позднее проявляются манипулирование предметами, хватание, толкание, игра с ними, рассматривание, использование игрушек по их назначению и многое другое;

2) коммуникативная активность (П-2) направлена на контакт с мамой и другими окружающими. Она может выражаться в разном возрасте через обращение взгляда, поворот лица, головки в сторону субъекта интереса, эмоциональном оживлении и реагировании; проявляется также в визуальном контакте со взрослым, следовании за ним в помещении, инициации общения со взрослым, участии в совместных «перекличках» и многом другом.

3) интенционально-мотивационные проявления (П-3), отражающие направленность малыша на получение того или другого предмета из своего окружения. Например, малыш тянется к игрушке, карабкается, чтобы достать ее; сидя за общим столом, выбирает себе со стола кусок сыра, чтобы съесть его, и т.п. (Белова, 2005, 2008);

4) отсутствие поведенческих проявлений (П-4) в тех ситуациях, где происходит голосовое реагирование ребенка.

В каждом записанном в результате наблюдения эпизоде экспериментатор производил кодирование зарегистрированных элементов - как поведения, так и голоса малыша. Оба показателя придавались каждому событию. В случаях отсутствия поведенческих проявлений (П-4) фиксировался только характер голоса. Данные анализа заносились в специальный бланк.

Подсчитывалось число каждого из трех видов голосовых проявлений младенца и каждой из четырех форм его поведения. Затем вычислялось количество наблюдаемых сочетаний.

Необходимо признать, что разработанные методические приемы при всей их необходимости, связанной с целями работы, оказываются несовершенными и вносят определенный шум в представляемые для обработки результаты. Прежде всего, применяемые приемы неизбежно обедняют любое «живое голосовое звучание» и «живое двигательное проявление». Далее, анализ записей производился экспертами, которые после некоторой тренировки и при обычной совместной работе не менее двух экспертов приобретают, как мы надеемся, навыки к проводимой работе. Однако человеческий фактор играет существенную роль. Эксперты могут ошибаться в квалификации голосовых и двигательных реакций малыша, пропускать значимые оттенки ситуации. Все сказанное мы, однако, не считаем основанием для оценки полученных данных как бракованных, скорее как приблизительных, отражающих тренд процесса.

Сознавая слабые методические стороны работы, мы предлагаем рассматривать полученные в работе фактические результаты как предварительные, а все исследование в целом как науиныци проект, позволяющий наметить направление пути происхождения осмысленного слова у маленького ребенка с момента его рождения до года. 


\section{Результаты}

После проведения описанного выше анализа возникает возможность раздельно и в наглядной форме описать интересующие нас качественные особенности, происходящие в истории развития как голосовых, так и познавательно-поведенческих форм в раннем возрасте ребенка.

Тренд развития собственно голосовой подсистемы показан на рисунке 1.

Рисунок 1 показывает, что голос младенца, целиком негативный поначалу, качественно меняется после первого месяца. К раннему негативному его компоненту, который в известной мере сохраняется значительную часть детства, добавляется с начала 2-го месяца позитивный голос. Возникают и разрастаются позитивные звучания. На 3-4-м месяце проявляется чувствитель- ность к звучаниям окружающей речи. Возникают звуки, имеющие фонетическое сходство со звучащей вокруг речью: гласноподобные, согласноподобные, слогоподобные и др. (Ляксо, 2010). В каждом выделенном периоде происходит смена одной формы голосовых проявлений на последуюшую, новую форму.

Данные рисунка 1, как мы полагаем, ориентировочно могут быть связаны с влиянием следующих факторов:

a) особенностями звучащей вокруг речи окружающих;

б) готовностью перцептивного слухового аппарата к дифференцированито воспринимаемых речевых звуков;

в) спонтанным развитием артикуляторного механизма младенца;

г) развитием имитационных возможностей младенца в отношении звуков речи окружающих.

Эти данные можно понимать в том смысле, что голосовая подсистема в

Рисунок 1

Развитие голосовой линии на первом году жизни

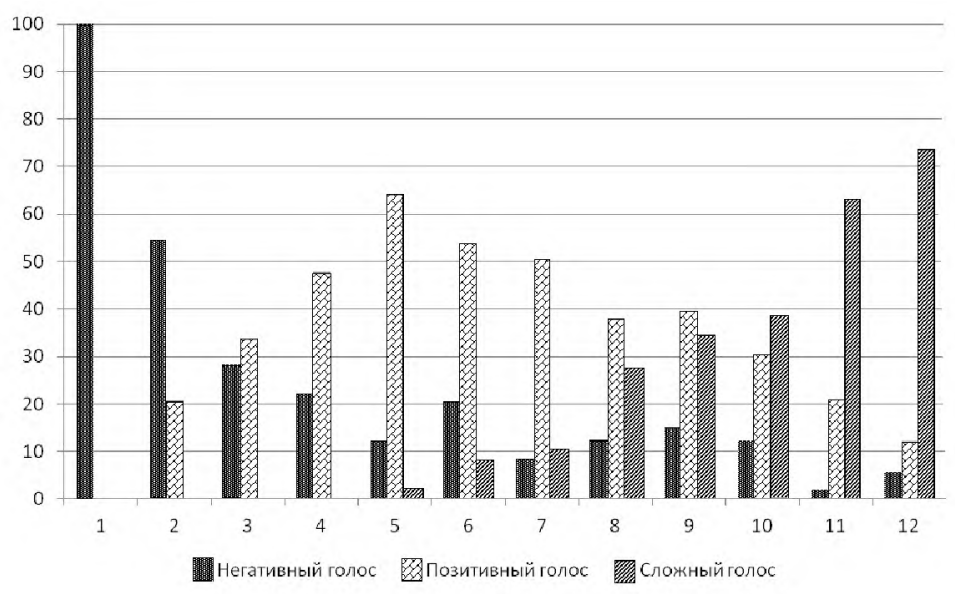

Примеиание. По оси Y - средний процент к общему количеству единиц анализа в периоде; по оси X - возраст ребенка (месяцы). 
основном не направлена на осуществление адаптивной, поведенческой функции. С определенным вычетом можно считать, что для общей характеристики голосовой линии ее можно представить как «слепой» элемент развития адаптивной системы младенца.

Совсем иначе по сравнению с голосом проходит развитие познавательно-действенной линии активности младенца от 0 до 12 мес. Траектория ее развития показана на рисунке 2.

Разъясним способ построения этого рисунка. Дело в том, что специфика поведенческой линии не имеет непосредственного числового выражения. Поведение меняется и обогащается по своему качественному составу. Построение диаграммы на рисуноке 2 в методическом плане потребовало введения специальных вспомогательных средств. Для разработки таких вспомогательных форм использовались поведенческие шаги, свидетельствующие о ментальнокогнитивном развитии младенца. Каждый из шагов принимался за условную единицу развития, отмеряемую по вертикальной оси. Этими шагами признаны уже перечисленные выше акты: а) ориентировочнопознавательное поведение (поисковые движения глаз и др.), б) коммуникативное проявление (комплекс оживления), в) интенционально-мотивационные реакции, а также г) включение вербальных сигналов, сложный голос, первые слова. Суммарное количество таких шагов принималось за совокупный показатель развития на каждом месяце. В диаграмму включался каждый новый шаг. Увеличение количества однородных шагов не отражалось на диаграмме,

Рисунок 2

Развитие поведенческо-действенной линии на первом году жизни с включением вербальных сигналов

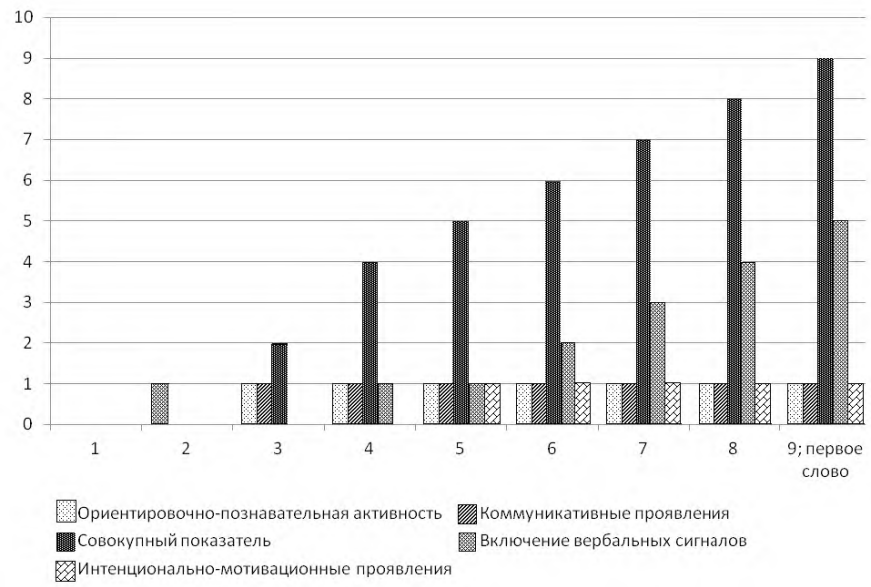

Примемание. По оси Y - средний процент к общему количеству единиц анализа в периоде; по оси X - возраст ребенка (месяцы). 
поскольку их количество на протяжении месяца - величина случайная, зависящая от того, какого характера эпизоды включены в анализ.

Поскольку на первом месяце в анализируемых материалах младенец, по нашим данным, не проявлял себя с поведенческой стороны, соответственно, этот период показан на диаграмме пустым. Вспомним, что развитие голоса, по рисунку 1, напротив, обнаруживает, что негативные голосовые реакции наиболее активны в этом периоде. С 1-го месяца включаются познавательно-действенные проявления (в форме поисковых движений глаз). Несколько позднее присоединяется социальный компонент (контакт с мамой). Далее, в определенные моменты отмечаются элементы усложнения познавательно-действенного репертуара. Новые проявления, раз появившись, нарастают в частоте, усложняются в своих проявлениях, но не исчезают, На рисунке 2 показано, ито происходит не смена форм реациования, как при развитии голоса (рисунок 1), а их последовательное накопление и расиирение. Таким образом, сравнение материалов рисунка 1 и рисунка 2 показывает разные по типу истории развития голосовой и поведенчески-действенной линий на первом году жизни младенца. Разница между ними обнаруживается в их центральных функциях: голос, как мы полагаем, в большей части своих проявлений - «слепой» элемент развития; в отличие от этого познавательно-действенная форма реагирования осуществляется как познающая, изменяющаяся система, действующая за счет восприятия, научения, адаптации к среде.
Сопоставление данных рисунка 1 и рисунка 2 показывает перемены в соотношении голосовых и поведенчески-действенных проявлений младенца в течение первого года. На 1-м месяце наблюдается связь вокализаций негативного типа только с реакциями чисто витального характера.

Со 2-3-го месяца по 7-й месяц включительно возникают и становятся более частыми вокализации нейтрально-положительного типа, нейтральные по отношению к поведенчески-действенным реакциям.

8-12-й месяцы отличны выраженным усилением голосовых форм сложного типа, сопутствующим преимущественно коммуникативным, а также ориентировочно-исследовательским действиям. Значимо менее частотными по сравнению с вторым периодом становятся проявления нейтрально-позитивного голоса в ориентировочно-исследовательском поведении и общении, негативного голоса при интенциональных и мотивационных формах поведения. Это иллюстрирует рисунок 2, где столбик включения вербальных сигналов все с большей активностью нарастает в 7-8-9-й месяцы.

Результаты в целом показывают общую динамику развития поведенческих реакций, а также тенденцию сближения в проявлении голосовых и общеповеденческих действенных актов.

$$
* * *
$$

В данном разделе статьи рассмат ривались результаты проведения эмпирической части исследования, направленного на познание пути развития начатков речи у младенца пер- 
вого года жизни. Хотя на основе полученных данных и возникло понимание некоторых новых сторон этого исключительно сложного процесса, ясно высветилась необходимость теоретического обсуждения еще одной важнейшей его стороны. Ею является включение психологического начала в ход общего раннего развития ребенка.

\section{Психологическая, субъективная составляющая в поведении младенца}

Важность и необходимость рассмотрения психологического начала в ходе общего раннего развития ребенка обусловлены тем, что без учета психологического (субъективного) компонента весь путь познания окружающего мира и освоения малышом речи, а также становление у него в будущем осмысленного языка лишаются своего коренного начала (Ушакова, 2015; Ушакова, Белова, 2015).

Простое наблюдение обнаруживает, что с самого раннего детства субъективные психологические переживания младенца в виде эмоционального отклика отчетливо проявляются вовне и улавливаются близкими людьми. Это относится уже к «комплексу оживления» (2-3 мес.). Реакция оживления инициируется голосом малыша, генетически связанным с эмоциями, эмоции - субъективное переживание. Прослеживая эту связь голоса и эмоций ребенка, следует признать психологическую составляющую очень ранним проявлением, возможно, и прирожденным, имманентным свойством голосовой активности младенца.
Что касается поведенчески-действенных форм реагирования младенца, то, как показывают материалы предыдущих разделов, они формируются у младенца под влиянием жизненных обстоятельств в роли инструмента познания и приспособления ребенка к меняющимся условиям сушествования. Эта роль поведенчески-действенных форм реагирования дает основание проследить их связь с возникновением зачаточных форм осмысленности. Рассмотрим для примера ситуацию развития начальных реакций познавательного характера - хватание предмета. Малыш тянется к интересному для него объекту, пытается схватить его, но не может правильно оценить расстояние до него и промахивается. У ребенка возникает неудовольствие. После неудачных попыток он может заплакать. Путем нескольких проб возникает обучение. При успешности действий малыш удовлетворен. Неприятное субъективное состояние сменяется более благоприятным, позитивным. Смена субъективного состояния приобретает тем самым способность отражать логику внешнего хода событий.

На этом примере мы видим, что в общем случае субъективная сторона реагирования младенца соответствует объективному ходу событий, его логике. В реагировании младенца можно благодаря этому видеть источник отражения субъектом причинно-следственных отношений с помощью психологических средств организма.

В соответствии со сказанным многочисленные литературные данные действительно показывают нарастающее обогащение ментально- 
когнитивной сферы младенца, начиная с первых дней его жизни. Тем самым в соответствии с нашей логикой происходит разрастание смысловой линии в его суб́ьективных переживаниях. Эта линия проходит разные стадии. Малыш «открывает смыслы» и наращивает интерес к своей деятельности при рассматривании внешних объектов, манипуляциях с игрушками, а затем и во взаимоотношениях с мамой. Младенец подолгу занимается фактически своего рода «познанием мира», когда он теребит игрушки: крутит их, пробует на вкус, сосет, бросает. Из манипулирования ими он извлекает свидетельства их возможностей. В схватывании, обсасывании, бросании, толкании игрушек и предметов он добывает знания об их проявлениях в условиях действия земных физических законов. Это можно видеть уже в возрасте 2-2.5 мес. жизни, когда малыш обнаруживает представление о простейших законах движения объектов и их взаимодействия, что показано в цикле классических экспериментов (Байаржон, 2000; Смит, 2000; и др.). Разнообразные формы игр ребенка со взрослыми имеют ту же направленность, только эти игры служат познанию форм и способов обращения с людьми. Круг переживаний, связанных с внешними событиями, расширяется от одной ступени развития ребенка к другой. В них все чаще включаются люди из окружения малыша. По данным Э. Бейтс (1984), к 8-9 мес. еще не говорящий ребенок способен участвовать в лабораторной ситуации, куда он помещен; понимает ее характер и цели, оценивает свои возможности, обращается за помощью к взрослому.
В публикациях показано раннее развитие обобщенных представлений: к 3-4 мес. возникает обобщенное понятие кошек, птиц, лошадей; к 7-8 мес. ребенок различает предметы, учитывает постоянство их размеров; в 9 мес. может отличить птицу от самолета (Сергиенко, 2008). Согласно нашим данным, в 3-4 мес. малыш обнаруживает возможность понимать слово, обозначающее человека. В ответ на вопрос «Где бабушка?» переводит взгляд на стоящую в стороне бабушку. По словесной просьбе дети с 5 мес. совершают простые действия передачи предмета взрослому (Соловьев, 1988). Через накопление соответствующих ощущений субъективное психологическое чувство, меняя свою сложность, постепенно вкрапливается в объективный процесс познания младенца.

Существенно, что, кроме непосредственных впечатлений, малыш рано начинает реагировать на отдельные слова, а затем, по объективным свидетельствам, понимать целые фразы. Если в 3-5 мес. он адекватно реагирует на слово «бабушка», то в 8-9 мес. на предложение пойти посмотреть, где находится интересующий его котенок, встает, самостоятельно идет к соседнему дому и находит привлекающий его объект. Понимание слышимой вокруг речи начинается с отдельных слов, а к годовалому возрасту достигает в определенной мере развитых речевых форм.

В целом мы видим, что к возрасту малыша в 9-11 мес. познавательнодейственная линия фактически хорошо подготовлена к тому, чтобы составить удовлетворительное для младенческого возраста семантиче- 
ское содержание будущего детского слова, возникающего на ее основе. Не отстает и голосовая линия, которая к рассматриваемому моменту накопила начальные возможности произнесения элементов, приближающихся к звучаниям используемого языка, и имеет прирожденную тенденцию присоединяться к текущим действиям ребенка. Можно думать, что подготовительный багаж созрел для возникновения первого слова.

В то же время для появления семантически значащего слова в этой ситуации, видимо, требуется акт слияния соответствующих элементов поведенческих линий. Используемые нами поведенческие проявления не дают оснований для решения этого вопроса. Мы приходим к заключению, что этот акт может быть описан на психофизиологическом и нейрофизиологическом уровне, что выходит в настоящее время за границы наших возможностей. В текущей литературе представлены интересные суждения по этому вопросу, заслуживающие дальнейшего обдумывания в нашем контексте (Валуева, Ушаков, 2015).

\section{Заключение}

Напомним общую структуру проведенной работы и рассмотрим более широкий контекст детской и общей психологии, куда, как кажется, вносят вклад полученные в работе материалы.

Мы помним, что в активно исследуемой области раннего детского и конкретно речевого онтогенеза нет решения важной проблемы - каким образом младенец овладевает способностью использовать осмысленное слово. Трудность и значимость проблемы заключаются в том, что акт употребления слова предполагает соединение в когнитивной системе ребенка двух несоизмеримых сущностей - протяженного звучащего слова и смыслового содержания (Чалмерс, 2013). Тем самым возникновение осмысленного слова в онтогенезе представляет своего рода «малую психофизиологическую проблему» в психологии, поскольку и в «малой», и в «большой проблеме» возникает общий вопрос - каков путь перехода от психологического состояния к физиологическому проявлению в одних случаях и от физиологического проявления к психологическому состоянию в других ситуациях.

Проведенная работа представляет исследование проблемы, каким образом младенец раннего возраста овладевает способностью использовать осмысленное слово. Полученные эмпирические факты позволяют, как кажется, наметить путь разработки этой проблемы. Базовый тезис проведенного исследования состоит в том, что реакции младенца раннего возраста (включая голосовые) рассматриваются как поведенческие по своему характеру, т.е. имеющие адаптивный характер. Соответственно, для эмпирического изучения младенческих реакций оказываются в основном достаточными современные понятия науки о нервной деятельности человека. Тем самым адекватным материалом для получения вызывающих доверие фактов оказываются аудио-видеозаписи. Для анализа записей нами была разработана соответствующая методика.

Методика позволила выявить историю развития основных линий 
поведенчески-функциональных проявлений пяти младенцев возраста от 0 до 12 мес. В результате проведенной работы описана целостная структура функциональных проявлений младенца обозначенного раннего возраста, связанная с его предсловесным развитием.

Показано, что поведенческие акты образуют систему, включающую голосовую и познавательно-действенную подсистемы. Обе названные линии развития находятся между собой в меняющемся по месяцам соотношении. Кроме названных, работают некоторые другие подсистемы, менее релевантные в нашем контексте, которые подробно не рассматриваются.

Полученные данные свидетельствуют о том, что необходимо связывать ранние истоки детской речи с формированием всей обозначенной системы, развитие которой начинается от рождения младенца. Момент появления первого произносимого ребенком слова предстает как итог определенного пути, пройденного в развитии разных линий детского поведения, подводящих к акту слияния элементов этих линий. Некорректно вести отсчет появления речи только от появления первых детских слов. Динамика формирования всей разноплановой предсловесной системы, возможно, сможет в будущем послужить предиктором успешности детского речевого развития. Этот вопрос требует, однако, специального изучения.

Соответственно структуре исследования встал вопрос об участии психологического (субъективного) компонента в когнитивном и специально речевом развитии младенца.
Нами разработано и теоретически обосновано представление о пробуждении и развитии субъективного чувства у младенца в рамках текущего поведенческого процесса. Показана его связь с логикой происходящих событий и приобретением ребенком зачаточных форм осмысленности. Разработка имеет гипотетический характер, но ее значение для понимания крупной темы развития и функционирования семантического компонента в структуре всей речевой и когнитивно-ментальной деятельности человека несомненно.

Акт слияния элементов поведенческих линий, как показывают современные данные, по всей вероятности, происходит на нейрофизиологическом уровне в результате взаимодействия нейронных сетей.

Предложенный подход обнаруживает преждевременность представления, согласно которому взаимодействие слова и мысли происходит путем непосредственного взаимодействия психического и физиологического на одной специализированной нервной клетке (Соколов, 2004). Такая позиция, возможно, когда-нибудь станет убедительной, но только после получения соответствующих фактов.

Описанная здесь работа представила научный проект, обозначивший направление пути по разработке названной проблемы. Этот подход опирается на выявление истории возникновения слова у маленького ребенка при последовательном использовании преимущественно поведенческих проявлений младенца и рассмотрении их развития на основе современных понятий науки о нервной деятельности человека. 


\section{Литература}

Байаржон, Р. (2000). Представления младенщев о скрытых объектах. Нностранная психолодия, $12,13-35$.

Бейтс, Э. (1984). Интенции, конвенции и символы. В кн. Психолингвистика (с. 50-103). М.: Прогресс.

Белова, С. С. (2005). Интенциональные явления на раннем этапе развития речи. В кн. Н. В. Уфимцева, Т. Н. Ушакова (ред.), Язык. Сознание. Культура. Сборник статей (с. 99-109). M. Kaлlyza: Эйдос.

Белова, С. С. (2008). Возникновение интенций в раннем возрасте и их соотношение с речевым развитием. В кн.: Т. Н. Ушакова (ред.), Реиь ребенка: проблемы и решения. Коллективная монография (с. 147-168). М.: Изд-во «Институт психологии РАН».

Белова, С. С., Носуленко, В. Н., Ушакова, Т. Н. (2016). Использование видеонаблюдения для выявления скрытых процессов предречевого развития младенща. Экспериментальная психология, 9(2), 66-81.

Валуева, Е. А., Ушаков, Д. В. (2015). Сигнальная модель инсайта: от исторических предпосылок к эмпирическим предсказаниям. В кн. А. Д. Журавлева, Д. В. Ушаков, М. А. Холодная (ред.), Современиые исследования интеллекта и твориества (с. 15-48). М.: Изд-во «Институт психологии РАН».

Ляксо, Е. Е. (2010). Развитие реии. От первых звуков до сложных фраз. СПб.: Речь.

Сергиенко, Е. (2006). Раннее когнитивное развитие. М.: Изд-во «Институт психологии РАН».

Серков, А. Н., Бережной, Д. С. (2016). Эволюционньй подход к проблеме возникновения психики. В кн. Седьмая международная конференция по когнитивной науке. 20.06-24.06, Светлогорск, Россия (с. 537).

Смит, Л. (2000). Обладают ли младенцы врожденными структурами знания? Другая сторона вопроса. Иностраниая психология, 12, 35-49.

Соколов, Е. Н. (2004). Нейроны сознания. Психология. Журнал Высшей иколы экономики, 1(2), $3-15$.

Соловьев, В. Д. (1988). Понимание речи ребенком в сенсомоторном периоде развития. В кн. Т.Н. Ушакова (ред.), Теоретические и прикладные исследования психологи реии (с. 141-156). М.: Институт психологии АН СССР.

Томаселло, М. (2011). Истоки человеческого общения. М.: Языки славянских культур.

Ушакова, Т. Н. (2011). Рождение слова: Проблемы психологи реии и психолингвистики. М.: Издво «Институт психологии РАН».

Ушакова, Т. Н. (2015). Как возможно осмысленное слово у годовалого ребенка. Bопросы психологии, 1, 26-38.

Ушакова, Т. Н., Белова, С. С. (2015). Истоки психолингвистического развития младенца первого года жизни. Вотросы психолингвистики, 4, 182-195.

Чалмерс, Д. (2013). Сознаюицй ум: в поисках фулдаментальной теории. М.: УРСС.

Ссылки на зарубежные источники см. в разделе References после аналоязычног блока. 


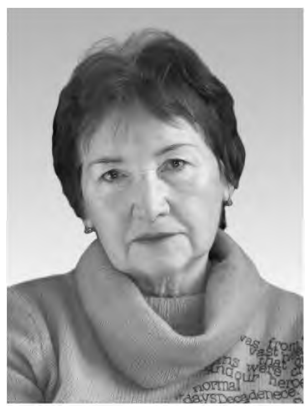

Ушакова Татьяна Николаевна - главный научный сотрудник, Институт психологии РАН, доктор психологических наук, профессор, академик Российской академии образования.

Сфера научных интересов: психология речи и языка, психолингвистика.

Контакты: tn.ushakova@gmail.com

\title{
The Origin and Development of the Rudiments of Speech in Babies during First Weeks and Months of Their Life (0-12)
}

\author{
T.N. Ushakova
}

${ }^{a}$ Institute of Psychology of Russian Academy of Sciences, 13 build. 1, Yaroslavskaya str., Moscow, 129366, Russian Federation

\begin{abstract}
The research project is presented that marks out the origin of the meaningful word in babies from the moment of their birth. The reactions of babies were viewed as the elements of their adaptive behavior. The database of the systematic video and audio recordings of behavior of the 5 babies from 0 to 12 months was formed, i.e. in the period that precedes the emergence of the child words - in a so-called "preverbal" period. A special method of analysis of the recordings was developed: 3 types of voice manifestations and 4 types of cognitive-active reactions were distinguished, as well as some other manifestations. In the process of observation the structure of reactions showed up, which includes at least 2 subsystems - vocal and cognitive-active. The diagrams, presented in the article, show the difference in the directions of development of the vocal and semantic subsystems. The author schematically showed the history of emergence of each of them. The early origins of the child speech are connected with the formation of this whole system, while its development starts from the birth of the baby. The author developed the theoretic conception of the origins and development of semantic (subjective) component of baby speech in the first months of life, emergence of rudimentary forms of meaningfulness, and showed the role of operant conditioning in production of first child words.
\end{abstract}

Keywords: origins of word in babies, vocal and cognitive-active reactions, psychological component of a word, meaningfulness.

\section{References}

Baillargeon, R. (2000). Predstavleniya mladentsev o skrytykh ob"ektakh [The notions of hidden objects in babies]. Inostrannaya Psikhologiya, 12, 13-35. (Transl. of: Baillargeon, R. (1987). Object 
permanence in 31/2-and 41/2-month-old infants. Developmental Psychology, 23(5), 655-664).

Bates, E. (1984). Intentsii, konventsii i simvoly [Intentions, conventions and symbols]. In Psikholingvistika [Psycholinguistics] (pp. 50-103). Moscow: Progress.

Belova, S. S. (2005). Intentsional'nye yavleniya na rannem etape razvitiya rechi [Intentional phenomena at the early stage of speech development]. In N. V. Ufimtseva \& T. N. Ushakova (Eds.), Yazyk. Soznanie. Kultura. Sbornik statei [Language. Consciousness. Culture. Collection of articles] (pp. 99-109). Moscow/Kaluga: Eidos.

Belova, S. S. (2008). Vozniknovenie intentsii v rannem vozraste i ikh sootnoshenie s rechevym razvitiem [The origin of intentions at an early age and their interrelation with development of speech]. In T. N. Ushakova (Ed.), Rech' rebenka: problemy i resheniya. Kollektionaya monografiya [Child's speech: problems and decisions. A collective monograph] (pp. 147-168). Moscow: Institute of Psychology of Russian Academy of Sciences.

Belova, S. S., Nosulenko, V. N., \& Ushakova, T. N. (2016). The use of video surveillance for identification of the internal processes of pre-verbal development in infant. Eksperimentalnaya Psihologiya, 9(2), 66-81. (in Russian)

Chalmers, D. (2013). Soznayushchii um: v poiskakh fundamental'noi teorii [The conscious mind: In search of a fundamental theory]. Moscow: URSS. (Transl. of: Chalmers, D. (1996). The conscious mind: In search of a fundamental theory. New York: Oxford University Press).

Dimitrova, N., Moro, C., \& Mohr, C. (2015). Caregivers interpret infants' early gestures based on shared knowledge about referents. Infant Behavior and Development, 39, 98-106.

Einspieler, C., Sigafoos, J., Bartl-Pokorny, K. D., Landa, R., Marschik, P. B., \& Bölte, S. (2014). Highlighting the first 5 months of life: General movements in infants later diagnosed with autism spectrum disorder or Rett syndrome. Research in Autism Spectnum Disorders, 8(3), 286-291.

Fjørtoft, T., Einspieler, C., Adde, L., \& Strand, L. I. (2009). Inter-observer reliability of the "Assessment of Motor Repertoire-3 to 5 Months" based on video recordings of infants. Early Human Development, 85(5), 297-302.

Hall, R. A. S., De Waard, I. E. M., Tooten, A., Hoffenkamp, H. N., Vingerhoets, A. J. J. M., \& van Bakel, H. J. A. (2014). From the father's point of view: How father's representations of the infant impact on father-infant interaction and infant development. Early Human Development, 90(12), 877-883. doi:10.1016/j.earlhumdev.2014.09.010

Kuhl, P. K. (2004). Early language acquisition: cracking the speech code. Nature Revieres Neuroscience, 5(11), 831-843.

Lyakso, E. E. (2010). Razvitie rechi. Ot pervykh zzukov do slozhnykh fraz [Development of speech. From first sounds to complex phrases]. Saint Petersburg: Rech'.

Marschik, P. B., Pini, G., Bartl Pokorny, K. D., Duckworth, M., Gugatschka, M., Vollmann, R., ... Einspieler, C. (2012). Early speech-language development in females with Rett syndrome: focusing on the preserved speech variant. Developmental Medicine and Child Neurology, 54(5), 451-456.

Roy, B. C., Frank, M. C., DeCamp, P., Miller, M., \& Roy, D. (2015). Predicting the birth of a spoken word. Proceedings of the National Academy of Sciences, 112(41), 12663-12668.

Roy, D., Patel, R., DeCamp, P., Kubat, R., Fleischman, M., Roy, B., \& Levit, M. (2006). The Human Speechome Project. In P. Vogt, Y. Sugita, E. Tuci, \& C. Nehaniv (Eds.), Symbol grounding and beyond (pp. 192-196). Berlin/Heidelberg: Springer.

Saint-Georges, C., Cassel, R. S., Cohen, D., Chetouani, M., Laznik, M. C., ... Muratori, F. (2010). What studies of family home movies can teach us about autistic infants: A literature review. Research in Autism Spectrum Disorders, 4(3), 355-366. 
Sergienko, E. (2006). Rannee kognitionoe razvitie [Early cognitive development]. Moscow: Institute of Psychology of Russian Academy of Sciences.

Serkov, A. N., \& Berezhnoi, D. S. (2016). Evolyutsionnyi podkhod k probleme vozniknoveniya psikhiki [Evolutionary approach to the problem of origins of mind]. In Sed'maya mezhdunarodnaya konferentsiya po kognitivnoi nauke. 20.06-24.06, Svetlogorsk, Rossiya [7th International conference on cognitive science] (p. 537).

Smith, L. (2000). Obladayut li mladentsy vrozhdennymi strukturami znaniya? Drugaya storona voprosa [Do the babies have innate structures of knowledge? The other side of the question]. Inostrannaya Psikhologiya, 12, 35-49.

Sokolov, E. N. (2004). Neurons of consciousness. Psychology. Joumal of Higher School of Economics, 1(2), 3-15. (in Russian)

Soloviev, V. D. (1988). Ponimanie rechi rebenkom v sensomotornom periode razvitiya [Understanding of speech by a child in a sensory motor period of development]. In T. N. Ushakova (Ed.), Teoreticheskie i prikladmye issledovaniy a psikhologii rechi [Theoretical and applied studies in psychology of speech] (pp. 141-156). Moscow: Institute of Psychology of Academy of Sciences of USSR.

Tomasello, M. (2013). Istoki chelovecheskogo obshcheniya [The origins of human communication]. Moscow: Yazyki slavyanskikh kul'tur. (Transl. of: Tomasello, M. (2008). Origins of human communication. Cambridge, MA/London, UK: A Bradford Book/The MIT Press).

Ushakova, T. N. (2011). Rozhdenie slova: Problemy psikhologii rechi i psikholingvistiki [The birth of a word: Issues of psychology of speech and psycholinguistics]. Moscow: Institute of Psychology of Russian Academy of Sciences.

Ushakova, T. N. (2015). How the usage of the intelligent word can appear in one-year old infants. Voprosy Psikhologii, 1, 26-37.

Ushakova, T. N., \& Belova, S. S. (2015). Origins of psycholinguistic development of infants during their first year of life. Joumal of Psycholinguistics, 26(4), 182-195. (in Russian)

Valueva, E. A., \& Ushakov, D. V. (2015). Signal'naya model' insaita: ot istoricheskikh predposylok k empiricheskim predskazaniyam [The signaling model of insight: from historical preconditions to empirical predictions]. In A. D. Zhuravleva, D. V. Ushakov, \& M. A. Kholodnaya (Eds.), Sovremennye issledovaniya intellekta $i$ toorchestva [Modern research on intellect and creativity] (pp. 15-48). Moscow: Institute of Psychology of Russian Academy of Sciences.

Zappella, M., Einspieler, C., Bartl-Pokorny, K. D., Krieber, M., Coleman, M., Bцlte, S., \& Marschik, P. B. (2015). What do home videos tell us about early motor and socio-communicative behaviours in children with autistic features during the second year of life - An exploratory study. Early Human Development, 91(10), 569-575. 